\title{
Degradation of the electrospun silica nanofiber in a biological medium for primary hippocampal neuron - effect of surface modification
}

This article was published in the following Dove Press journal:

International Journal of Nanomedicine

26 February 2016

Number of times this article has been viewed

\author{
Z Vivian Fengl,* \\ Wen Shuo Chen ${ }^{2, *}$ \\ Khomson Keratithamkul' \\ Michael Stoick' \\ Brittany Kapala ${ }^{3}$ \\ Eryn Johnson ${ }^{3}$ \\ An-Chi Huang ${ }^{2}$ \\ Ting Yu Chin ${ }^{4}$ \\ Yui Whei Chen-Yang ${ }^{2}$ \\ Mong-Lin Yang ${ }^{3}$ \\ 'Chemistry Department, Augsburg \\ College, Minneapolis, MN, USA; \\ ${ }^{2}$ Department of Chemistry, Center \\ for Nanotechnology, Center for \\ Biomedical Technology, Chung \\ Yuan Christian University, Chung \\ $\mathrm{Li}$, Taiwan, Republic of China; \\ ${ }^{3}$ Department of Science, Concordia \\ University Saint Paul, Saint Paul, MN, \\ USA; ${ }^{4}$ Department of Bioscience \\ Technology, Chung Yuan Christian \\ University, Chung Li, Taiwan, Republic \\ of China \\ *These authors contributed equally \\ to this work
}

Correspondence: Mong-Lin Yang Department of Science, Concordia University Saint Paul, 1282 Concordia Avenue, Saint Paul, MN 55I04, USA

Tel + I 65I 64I 8220

Fax + | 65| 64| 629|

Email myang2@csp.edu

Yui Whei Chen-Yang

Department of Chemistry, Center for Nanotechnology, Center for Biomedical Technology, Chung Yuan Christian University, 200 Chung Pei Road, Chung Li, Taiwan 32023, Republic of China

Tel +866 32653317

Fax +88632653399

Email yuiwhei@cycu.edu.tw

\begin{abstract}
In this work, silica nanofibers (SNFs) were prepared by an electrospinning method and modified with poly-D-lysine (PDL) or (3-aminopropyl) trimethoxysilane (APTS) making biocompatible and degradable substrates for neuronal growth. The as-prepared SNF, modified SNF-PDL, and SNF-APTS were evaluated using scanning electron microscopy, nitrogen adsorption/desorption isotherms, contact angle measurements, and inductively coupled plasma atomic emission spectroscopy. Herein, the scanning electron microscopic images revealed that dissolution occurred in a corrosion-like manner by enlarging porous structures, which led to loss of structural integrity. In addition, covalently modified SNF-APTS with more hydrophobic surfaces and smaller surface areas resulted in significantly slower dissolution compared to SNF and physically modified SNF-PDL, revealing that different surface modifications can be used to tune the dissolution rate. Growth of primary hippocampal neuron on all substrates led to a slower dissolution rate. The three-dimensional SNF with larger surface area and higher surface density of the amino group promoted better cell attachment and resulted in an increased neurite density. This is the first known work addressing the degradability of SNF substrate in physiological conditions with neuron growth in vitro, suggesting a strong potential for the applications of the material in controlled drug release.
\end{abstract}

Keywords: silica nanofibers, electrospinning, dissolution, neurite density, surface modification

\section{Introduction}

Recent studies have pointed out the need for incorporation and utilization of biomaterial ${ }^{1-3}$ toward transplanting stem cells in the reconstruction of central nervous system, or regrowing severed nerves at injured sites of the peripheral nervous system. Specifically, researchers have identified desirable properties for such scaffolds to be three dimensional (3-D), bioactive, and biodegradable. ${ }^{4}$ In order to achieve the ideal chemical and mechanical properties in vitro, the organic-based biomaterials, such as a combination of gelatin and genipin, poly( $\varepsilon$-caprolactone), and poly(orthomethoxyaniline), have been successfully synthesized and utilized for neuronal tissue engineering. ${ }^{5-7}$ Although inorganic-based biomaterials have seen greater success in sensors, adsorbents, and medicines, ${ }^{8-11}$ their applications in tissue engineering have mainly focused on bone tissue engineering, ${ }^{11,12}$ utilizing their good mechanical strength and biocompatibility for in vivo implantation, with limited progress in neuronal tissue engineering. ${ }^{13}$ In our previous study, ${ }^{14}$ we have introduced a novel inorganic neuronal tissue engineering substrate, the chemically modified silica nanofibers (SNFs), which were electrospun to form biomimetic framework of the extracellular matrix and sol-gel 
prepared to contain mesoporous structures, which can further be utilized for the delivery and release of regulatory biologics. Electrospun materials used for biological applications, such as drug carriers or tissue scaffolds, could be made by direct incorporation of biomaterials in structural nanofibers using multiple-fluid electrospinning ${ }^{15-17}$ or after treatment of electrospun nanoproducts. ${ }^{18,19}$ Our electrospun mesoporous silica scaffold of the latter method allows physical adsorption of regulatory biomolecules after construction of the scaffold framework, as opposed to the common practice in organic-based electrospun fibers that blends or encapsulates the biologics while forming the fibers. This discrepancy prevents exposure of the biomolecules to potential denaturizing conditions. ${ }^{20-22}$

In this work, we extend our investigation to better understand this novel scaffold for cell growth with the built-in potential for drug release by examining the biodegradability of this material with different surface modifications in a physiologically relevant environment, the degradation process of the material, and the biocompatibility of the material in supporting primary neuron growth and differentiation. A literature survey of synthetic biodegradable materials for tissue engineering has mainly resulted in organic polymers that required enzymes or specific chemical conditions. For example, degradation of polyether-polyurethanes depends on cholesterol esterase, ${ }^{23}$ poly( $\varepsilon$-caprolactone) fibers require lipase,${ }^{24,25}$ poly(L-lactide) needs proteinase $\mathrm{K},{ }^{26}$ and poly(1,3diamino-2-hydroxypropane-co-polyol sebacate) degrades at low $\mathrm{pH} .{ }^{27}$ In addition, enzymatic degradation of most organic polymeric nanofibers takes months and thus the embedded biologics might not be readily available to release early on for aiding guidance or repair unless local enzyme concentrations are augmented in situ. ${ }^{28}$ As for studies on implantable inorganic biomaterials, silica and titanium oxide are the main materials reported due to their biocompatibility. ${ }^{29-31}$ Although biodegradability of mesoporous silica nanoparticles has been extensively studied as drug delivery vehicles with well-documented dissolution behavior in high ionic physiological conditions, ${ }^{32,33}$ to our knowledge, no known studies have investigated the degradation of SNF for tissue engineering. Neuron regeneration has been reported to occur within 21 days in in vivo study ${ }^{34}$ and requires particular drug/cell signal support in vitro. ${ }^{35}$ It is desirable to have materials that degrade within the timeframe of weeks and is in line with the expectation to help guide early cell differentiation. The biocompatibility of SNF in tissue engineering has been demonstrated in recent literature. Ravichandran et $\mathrm{al}^{36}$ reported the growth of osteoblast-like cells (MG63) on SNF when cultured for 3 days. This report only alluded to the possibility that dissolved silicic acid may promote bone cell growth, yet no experimental evidence on the actual dissolution of the material was provided. This may be due to the short incubation time that was insufficient to allow such observation. Another example presented by Yamaguchi et $\mathrm{al}^{37}$ reported the growth of CHO-K1 and HepG2 cells on SNF when cultured for up to 14 days. In this particular work, although the incubation time was long, the cancerous nature of the cells had populated and almost covered the material surfaces making it difficult to observe any morphological changes. Indeed, during our previous work with neural stem/progenitor cells, ${ }^{14}$ although we had noticed some signs of material dissolution due to the proliferative nature of the cells, the substrates were usually covered within 5 days, impeding the observation of material dissolution. Aiming to observe the dissolution of SNFs as well as material-cells interactions, we employed primary neurons as our cell model. Primary neuronal cells allow observations of material-cell interaction more clearly without any concerns for cell overgrowth, yet it is still in alignment with our goal of developing SNF as a biomaterial for neuronal growth.

In this study, we demonstrate the feasibility of surfacemodified SNFs with both physically absorbed poly-Dlysine (PDL) and covalently attached (3-aminopropyl) trimethoxysilane (APTS) as biocompatible and degradable scaffold materials for neuronal tissue engineering. We also showcase that SNF in physiological $\mathrm{pH}$ and ionic strength media degrades without the need of specific chemical conditions or the presence of enzymes. Finally, our data indicate the amount of degradation product released is nontoxic to the neuronal cells. Together, the tunability of the material depending on surface modifications and the biocompatibility of the biodegradable material allows for potential applications in controlled release of drugs or biologics for cell development, growth, or regeneration.

\section{Materials and methods Materials}

Tetraethyl orthosilicate (TEOS) was purchased from Acros Organics (Thermo Fisher Scientific, Waltham, MA, USA). Polyvinyl pyrrolidone (PVP; the average molecular weight $\left[M_{\mathrm{w}}\right]=1,300,000 \mathrm{~g} / \mathrm{mol}$ ) and phosphate-buffered saline (PBS) were purchased from Sigma-Aldrich Co. (St Louis, MO, USA). Electrospun SNFs were coated with either PDL (Sigma-Aldrich Co.) or APTS (Acros Organics). All chemicals were used without further purification. 


\section{Preparation, surface modification, and characterization of SNF substrates}

The SNFs were prepared by the electrospinning method as reported earlier. ${ }^{14}$ Briefly, $0.95 \mathrm{~g}$ of TEOS, $3.15 \mathrm{~g}$ of ethanol, $2.0 \mathrm{~g}$ of water, and $0.04 \mathrm{~g}$ of formic acid were mixed with PVP and stirred for 1 hour at room temperature. The solution was electrospun from plastic syringe with a needle diameter of $0.7 \mathrm{~mm}$ and at a flow rate of $0.9 \mathrm{~mL} /$ hour. A high voltage $(16 \mathrm{kV})$ was applied to the tip of the needle attached to the syringe. The resulting silica/PVP composite fibers were collected on an $18 \mathrm{~mm}$ cover slip placed on a flat aluminum plate collector kept at a distance of $10 \mathrm{~cm}$ from the needle tip. The pure SNFs were obtained by calcination of the silica/ PVP composite fibers for 3 hours at $450^{\circ} \mathrm{C}$ to remove PVP and solvent residues. In order to allow for better cell attachment, the silica surfaces were functionalized with amino groups. This was done in two ways for comparison: coating the surfaces with PDL or APTS. For PDL-treated surfaces, SNFs (denoted SNF-PDL) or cover slips (denoted coverslipPDL) were immersed in $0.1 \mathrm{mg} / \mathrm{mL}$ of PDL for an hour, and then rinsed three times with sterile distilled water, and air dried at room temperature for 1 hour. For APTS-modified
SNF (SNF-APTS), the SNF substrates were immersed in $3 \mathrm{M}$ APTS in ethanol solution for 24 hours at room temperature. ${ }^{14}$ Figure 1A illustrates coverslip-PDL, as a positive control, which is a two-dimensional (2-D) surface coated with PDL via physical interactions; Figure 1B, SNF-PDL, a 3-D surface of SNF physically coated with PDL, and Figure 1C, SNF-APTS, a 3-D surface of SNF chemically coated with APTS via covalent linkages. The substrates were then rinsed with distilled water repeatedly and dried at $100^{\circ} \mathrm{C}$ for 30 minutes. The morphologies of the as-prepared substrates were observed by an S-3500N field emission scanning electron microscopy (SEM; Hitachi Ltd., Tokyo, Japan). The diameters of the fibers $(n=40-60)$ were measured from SEM images using ImageJ analysis software. To measure the specific surface area of the as-prepared nanofibers, the nitrogen adsorption/desorption isotherms were measured on a Tristar 3000 analyzer (Micromeritics, Norcross, GA, USA) and analyzed with the Brunauer-Emmett-Teller (BET) method. Water contact angles were measured using an FTA 125 analyzer (First Ten Angstroms, Portsmouth, VA, USA) at ambient temperature. At least five $4 \mu \mathrm{L}$ water droplets were very carefully and separately dropped onto
A

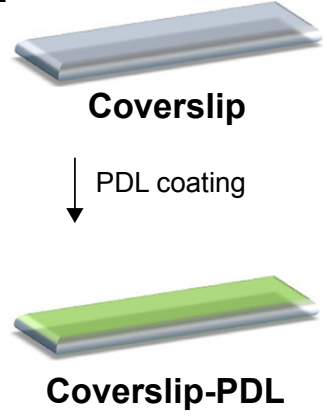

Physical absorption of PDL onto coverslip

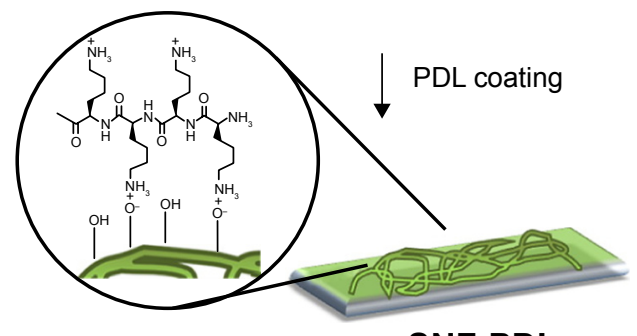

SNF-PDL

Physical absorption of PDL onto coverslip with silica nanofiber
C

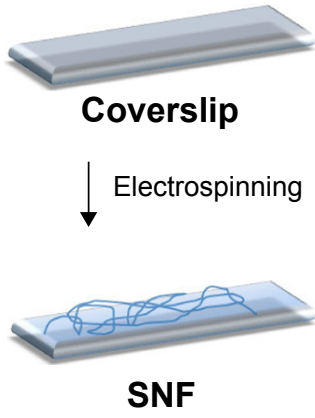

Coverslip with silica nanofiber

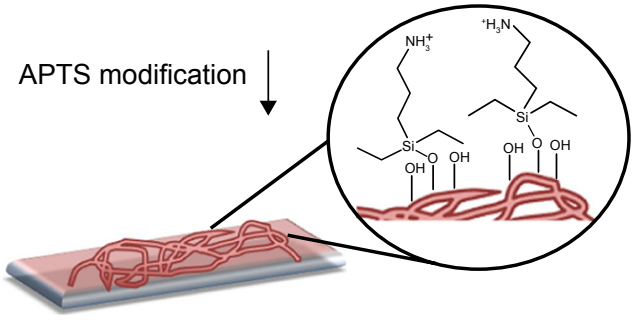

SNF-APTS

Covalent binding of APTS onto coverslip with silica nanofiber

Figure I Schematic of the three surface conditions tested.

Notes: (A) A 2-D coverslip surface coated with PDL via physical absorption (coverslip-PDL); (B) a 3-D SNF surface coated with PDL via physical absorption (SNF-PDL); and (C) a 3-D SNF surface with APTS via covalent interaction (SNF-APTS).

Abbreviations: 2-D, two-dimensional; SNF, silica nanofiber; PDL, poly-D-lysine; coverslip-PDL, poly-D-lysine-treated coverslip; 3-D, three-dimensional; SNF-PDL, poly-Dlysine-treated silica nanofiber; APTS, (3-aminopropyl) trimethoxysilane; SNF-APTS, (3-aminopropyl) trimethoxysilane-modified silica nanofiber. 
different positions of the sample surface. The average value of the contact angles of all the droplets (at least 15 droplets) measured from three different samples was calculated and adopted as the water contact angle.

\section{Primary rat hippocampal neuron culture}

Embryonic day 18 rat hippocampi were purchased commercially from BrainBits Company (Springfield, IL, USA) and dispersed and cultured in serum-free NbActiv1 media (BrainBits) at $37^{\circ} \mathrm{C}$ in a humid atmosphere with $5 \% \mathrm{CO}_{2}$ according to the previous studies. ${ }^{38,39}$ The live cells were counted using trypan blue exclusion assay in a hemocytometer. The SNF substrates on the coverslips were placed under the ultraviolet radiation overnight before use. Cells were seeded and grown at a density of $5.26 \times 10^{3}$ cells $/ \mathrm{cm}^{2}$ onto the desired surfaces of substrates. Half of the medium was replaced every 2-3 days.

\section{Silica dissolution study}

The dissolution experiments were conducted to evaluate the effect of the porous structure on dissolution of the asprepared SNF substrates. The as-prepared SNF substrates were incubated in a 12 -well plate at $37^{\circ} \mathrm{C}$ in PBS (without neuron) or NbActiv1 media (with neuron) for an extended period of time. After 6 days and 11 days in $0.010 \mathrm{M} \mathrm{PBS}$, fiber morphology was observed with SEM. The fiber diameters in SEM images were analyzed with ImageJ software.

The silicon contents of the solutions collected from each substrate incubating well were examined periodically with inductively coupled plasma atomic emission spectroscopy (ICP-AES; PerkinElmer Inc., Waltham, MA, USA). The solution was filtered with a $0.45 \mu \mathrm{m}$ membrane filter, and the silicon concentration in the filtrate was determined in a 20\% $\mathrm{HCl}$ solution matrix by an Optima 3300 DVTM ICPAES, with a cyclonic chamber (SCP Science, BaieD'Urfe, Quebec, Canada) and a Gem Cone nebulizer (PerkinElmer Inc). In total, 1,000 mg/L stock solutions of high-purity single-element standard solutions (SCP Science) of silicon $(4 \% \mathrm{~F}[\mathrm{v} / \mathrm{v}])$ and yttrium $\left(2 \% \mathrm{HNO}_{3}[\mathrm{v} / \mathrm{v}]\right)$ were used for standard preparation for ICP-AES measurements. All dissolution studies were performed with at least three biological replicates (ie, different substrates) and three technical replicates (ie, multiple readings of the same substrate), with an average and a standard deviation reported.

\section{Immunocytochemistry staining}

Fluorescence immunocytochemistry was conducted according to the previous study. ${ }^{40}$ Cells were fixed with $4 \%$ formaldehyde for 20 minutes. The cells were then permeabilized using $0.25 \%$ Triton $\mathrm{X}-100$ in PBS for 15 minutes and blocked with $10 \%$ bovine serum albumin for 1 hour at $37^{\circ} \mathrm{C}$. The cells were incubated with rabbit antimicrotubuleassociated protein 2 antibody (1:300 dilution; Santa Cruz Biotechnology Inc., Dallas, TX, USA) for 1 hour at $37^{\circ} \mathrm{C}$. These cells were then incubated with Alexa Fluor 546 goat anti-rabbit IgG antibody (1:100 dilution; Thermo Fisher Scientific, Waltham, MA, USA) for 1 hour at $37^{\circ} \mathrm{C}$ while the cell nuclei were detected subsequently with 4',6-diamidino2-phenylindole (DAPI; Sigma-Aldrich Co.) for 15 minutes at $25^{\circ} \mathrm{C}$. The cells were then visualized either on Nikon A1 spectral fluorescent confocal microscope (Nikon Corporation, Tokyo, Japan) for immunostaining of biomarkers or on Nikon E800 hyperspectral fluorescence microscopy (Nikon Corporation) for quantification of neurites, and images were acquired using Nikon NIS Elements software. For quantification of length of neurites, images were acquired by automating the acquisition using $20 \times$ objectives of 16 images stitched together with $5 \%$ overlap into one large image, thereby allowing high enough resolution as well as large enough view field for analysis. Twenty of these large stitched images were analyzed for each condition using the NeuronJ software plugin of ImageJ to trace the length of each neurite. Average neurite density was calculated by counting the number of neurites in each image and then averaging the number of all 20 view fields.

\section{Cell viability}

Neuronal viability was determined using LIVE/DEAD assay kit (Thermo Fisher Scientific), containing calcein acetoxymethyl ester and ethidium homodimer-1 at a concentration of $1 \mu \mathrm{M}$ each, which was added to neurons at 5 days in vitro (5 DIV) seeded on the as-prepared SNF substrates according to the previous studies. ${ }^{41,42}$ The cells were subsequently incubated with the dyes for 5-10 minutes and then 16-20 images were taken with fluorescence microscope. Primary neuron cells stained with a cell-permeable dye, calcein acetoxymethyl ester, were counted as live cells, whereas primary neuron cells stained with a membrane-impermeable DNA-binding dye, ethidium homodimer-1, were counted as dead cells. The percentage of viable cells was calculated based on the ratio of viable cells to total cell population in each well $(n>800)$.

\section{Cell morphology study}

The morphology of the cells on the coverslip-PDL, which is conventionally used for culturing the hippocampal neurons, ${ }^{43}$ along with the as-prepared substrates was observed with 
SEM. On day 10 and day 15, the substrates with cells were collected, fixed with formaldehyde, and sequentially dehydrated through an increasing concentration gradient of alcohol followed by critical point drying with Bis (trimethylsilyl) amine. The samples were sputter coated with gold-palladium (Au-Pd) for observation on an S-4700 SEM (Hitachi Ltd.).

\section{Statistical analysis}

All experiments were at least triplicated, and all the data were reported as mean \pm standard deviation. Experimental outliers were tested using the $Q$-test. Statistical analysis was carried out using unpaired $t$-test and one-way analysis of variance. The statistical significance was set as $P<0.01$.

\section{Results and discussion Characterization of surface-modified electrospun SNFs}

It is known that substrates with different physical and chemical properties affect cell attachment and growth through activating different signaling pathways. ${ }^{13}$ To characterize the surface properties of the surface-modified SNF substrates, SEM, contact angle measurements, and BET isotherm analyses were conducted. The SEM micrographs showed that the fiber diameters of SNF $(254 \pm 79 \mathrm{~nm})$, SNF-PDL $(258 \pm 90 \mathrm{~nm})$, and SNF-APTS $(231 \pm 54 \mathrm{~nm})$ substrates did not change significantly (Figure $2 \mathrm{~A}-\mathrm{C}$; one-way analysis of variance, $P>0.1$ ). Although Figure $2 \mathrm{D}-\mathrm{F}$ is unable to show difference of surface roughness among SNF, SNFPDL, and SNF-APTS, the contact angle was increased from $20.21^{\circ} \pm 2.98^{\circ}$ for $\mathrm{SNF}$ to $41.59^{\circ} \pm 2.16^{\circ}$, and $120.0^{\circ} \pm 1.48^{\circ}$ for SNF-PDL, and SNF-APTS, respectively (Figure 2D-F insets), indicating that the surface of SNF was highly hydrophilic as expected (Figure 2D). The hydrophilicity was only slightly reduced when the substrates were physically coated with PDL (Figure 2E) and became highly hydrophobic when chemically modified with APTS (Figure 2F). The contact angles from the SNF-APTS substrates were significantly higher than those of the SNF substrate while the substrates maintained similar fiber density and morphology. The results indicated that the surface property was changed to become highly hydrophobic due to the presence of the amino groups, and the contact angles were varied with immersed time and APTS concentration, which are in agreement with previous reports. ${ }^{14,44} \mathrm{~A}$ drastic decrease in the corresponding specific surface areas determined by the BET theory was observed upon APTS treatment, as given in Table 1. SNF-PDL retained the highly porous structure with large surface areas, while SNF-APTS showed more than tenfold decrease in surface area. We assume that part of the APTS modification occurred in interior of the pores of SNF-APTS, resulting in a significant reduction in the surface area. ${ }^{14,45}$ The corresponding contact angles, fiber diameters, pore sizes, and specific surface areas of the three substrate materials are summarized in Table 1. The results demonstrated that SNF-PDL barely changed the
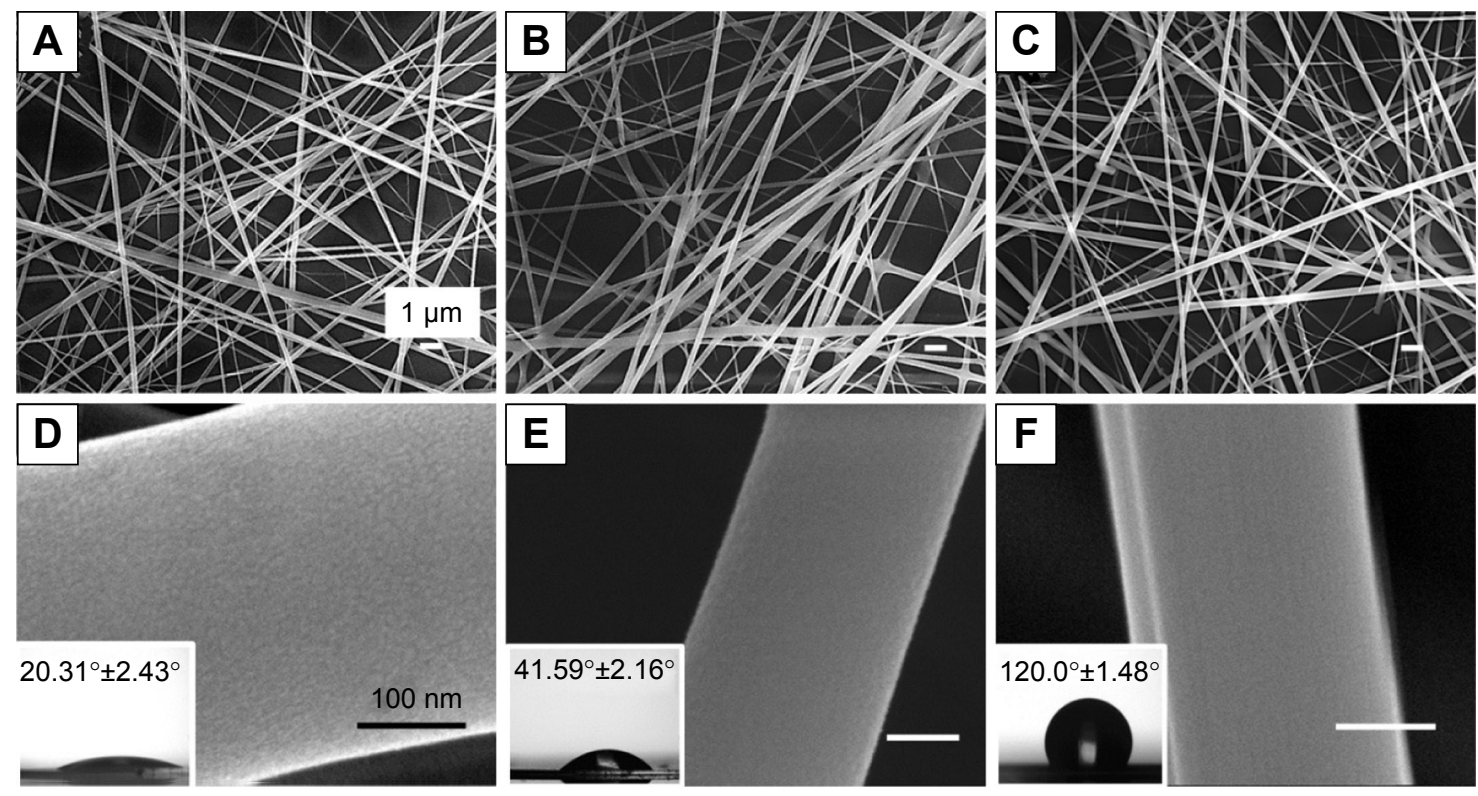

Figure 2 SEM images of SNF (A and D), SNF-PDL (B and E), and SNF-APTS (C and F).

Notes: Inset in (D-F) are contact angle images of the corresponding surfaces. Scale bars represent I $\mu \mathrm{m}$ in (A-C) and I00 nm for (D-F).

Abbreviations: SEM, scanning electron microscopy; SNF, silica nanofiber; SNF-PDL, poly-D-lysine-treated silica nanofiber; SNF-APTS, (3-aminopropyl) trimethoxysilanemodified silica nanofiber. 
Table I Characterizations of the SNF substrates with different surface modification

\begin{tabular}{lllll}
\hline Sample & $\begin{array}{l}\text { Fiber diameter } \\
(\mathbf{n m})\end{array}$ & $\begin{array}{l}\text { Contact } \\
\text { angle }\left({ }^{\circ}\right)\end{array}$ & $\begin{array}{l}\text { Pore size } \\
(\mathbf{n m})\end{array}$ & $\begin{array}{l}\mathbf{S}_{\text {BET }} \\
\left(\mathbf{m}^{2} / \mathbf{g}\right)\end{array}$ \\
\hline SNF & $254 \pm 79$ & $20.31 \pm 2.43$ & 3.1 & 383 \\
SNF-PDL & $258 \pm 90$ & $41.59 \pm 2.16$ & 3.3 & 286 \\
SNF-APTS & $231 \pm 54$ & $120 \pm 1.48$ & 7.2 & 22 \\
\hline
\end{tabular}

Notes: The diameters of the fibers $(n=40-60)$ were measured from SEM images using ImageJ analysis software. Data were reported as average \pm standard deviation. Abbreviations: SNF, silica nanofiber; SNF-PDL, poly-D-lysine-treated silica nanofiber; SNF-APTS, (3-aminopropyl) trimethoxysilane-modified silica nanofiber; $\mathrm{S}_{\mathrm{BET}}$, surface area analyzed with the Brunauer-Emmett-Teller (BET) method.

structural porosity and surface hydrophilicity of SNF while SNF-APTS resulted in significant reduction in surface area and the hydrophilicity of SNF.

\section{Dissolution of surface-modified SNF substrates in physiological buffer}

To evaluate the effect of dissolution on fiber morphology, SNF, SNF-PDL, and SNF-APTS, immersed in PBS buffer at $37^{\circ} \mathrm{C}$ with daily buffer exchange, were examined using SEM. PBS was chosen for dissolution study to represent a typical media with biologically relevant $\mathrm{pH}$ and ionic strength, thus allowing us to examine the material dissolution behavior. Figure $3 \mathrm{~A}-\mathrm{C}$ shows that after 6 days of immersion, the fiber integrity of all the three samples still remains. However, after 11 days, Figure 3D and E reveals that the fibers of SNF and SNF-PDL are degraded, and the diameters of the fibers have slightly increased. Upon closer inspection shown in insets, it is found that the fibers are highly corroded, resulting in uneven edges, rough surfaces, and enlarged pores. In contrast, the SNF-APTS fibers did not show any significant changes in its surface morphology by day 11 (Figure 3F). In fact, the surface of SNF-APTS fibers still appears smooth, and not only the surface but also the cross-section of a broken fiber remains intact after 11 days of immersion, indicating that SNF-APTS fibers degrade much slower than the SNF and SNF-PDL fibers.

Figure 4 clearly revealed a significant increase in fiber width from $403 \pm 73 \mathrm{~nm}$ to $553 \pm 83 \mathrm{~nm}$ for SNF (unpaired $t$-test, $P<0.01)$ and from $388 \pm 94 \mathrm{~nm}$ to $483 \pm 87 \mathrm{~nm}$ for SNF-PDL substrate (Figure 4; unpaired $t$-test, $P<0.01$ ). This analysis demonstrated that the erosion of the fiber from the porous structure had led to the collapse of the 3-D tubular structure, resulting in the flattening of the fiber onto the glass substrate during dissolution. However, the width analysis of the SNF-APTS fibers did not change significantly (unpaired $t$-test, $P>0.01$ ), which is in agreement with fiber morphology observed in SEM images (Figure 3C and F). This may be attributed to the hydrophobicity of the SNF-APTS surface as indicated in Figure $2 \mathrm{~F}$, which reduced its solubility in the buffer solution and decreased the surface area as listed in Table 1.

In order to quantify the dissolved silica, the amount of silicon in SNF-incubating media was monitored using ICPAES. Figure 5 depicts the levels of silicon when SNF was
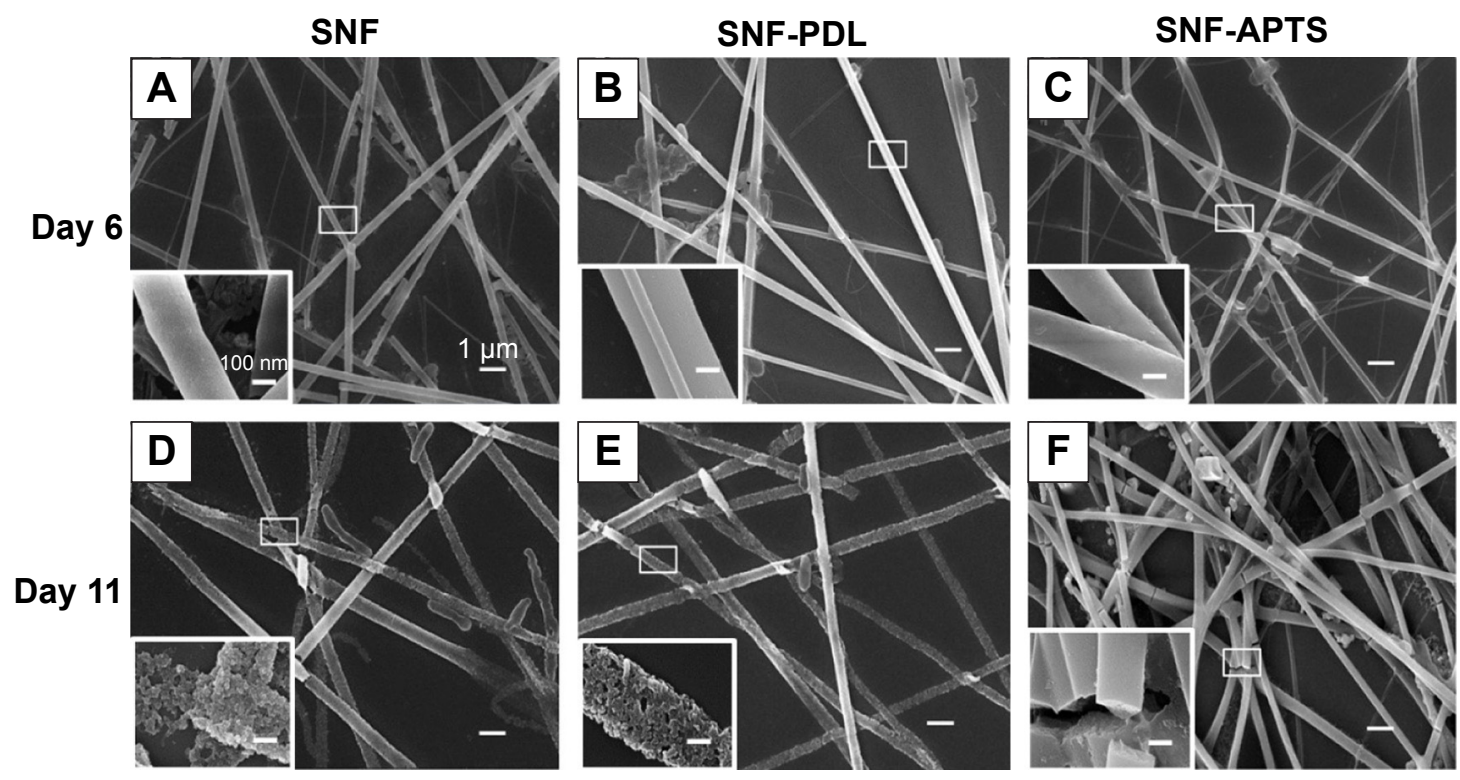

Figure 3 SEM images of SNF (A and D), SNF-PDL (B and E), and SNF-APTS (C and F).

Notes: As-prepared substrates are immersed in $10 \mathrm{mM}$ PBS for different time periods at $37^{\circ} \mathrm{C}$ : (A-C) after 6 days and (D-F) after II days. Inset in (D-F) are magnification of the corresponding surfaces. Scale bars represent I $\mu \mathrm{m}$ in $\mathbf{A}-\mathbf{F}$ and $100 \mathrm{~nm}$ for insets.

Abbreviations: SEM, scanning electron microscopy; SNF, silica nanofiber; SNF-PDL, poly-D-lysine-treated silica nanofiber; SNF-APTS, (3-aminopropyl) trimethoxysilanemodified silica nanofiber; PBS, phosphate-buffered saline. 


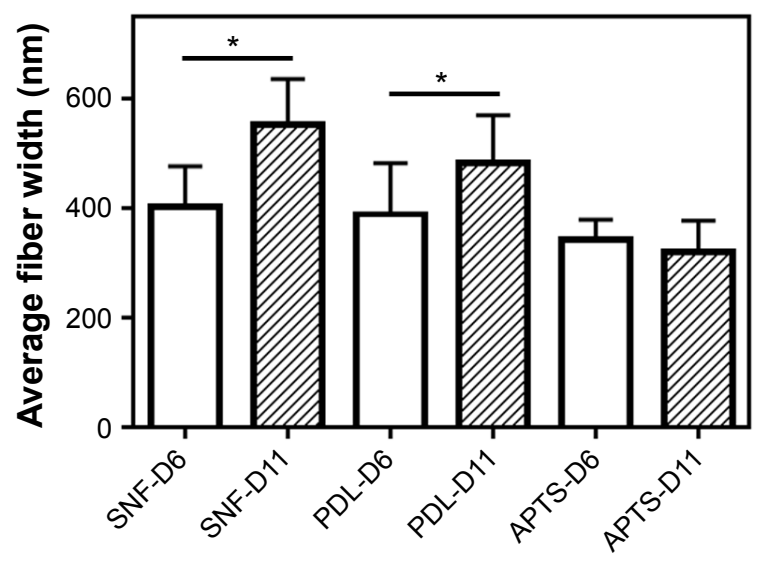

Figure 4 SNF fiber width analysis from SEM images.

Notes: Comparisons of average fiber width from SNF, SNF-PDL, and SNF-APTS $(* P<0.0 \mathrm{I})$. Unfilled, day 6; dash filled, day II after immersion in $\mathrm{PBS}$ at $37^{\circ} \mathrm{C}$. Abbreviations: SNF, silica nanofiber; SEM, scanning electron microscopy; SNF-PDL, poly-D-lysine-treated silica nanofiber; SNF-APTS, (3-aminopropyl) trimethoxysilanemodified silica nanofiber; PBS, phosphate-buffered saline.

incubated at $37^{\circ} \mathrm{C}$ in PBS buffer. Because the SNFs were supported on glass cover slip (also a silica-based material), the dissolution from coverslip-PDL was measured as the background amount of silicon, where a small amount was expected. The unmodified SNF substrate was not studied here because it could not be used for cell growth. As shown in Figure 5, although there was a slight increase in the amount of silicon dissolved from coverslip-PDLs as they aged in PBS buffer, the total amount of dissolved silicon from coverslips ( $<4 \mu \mathrm{g}$ up to day 22) was insignificant when compared to the amount of silicon dissolved from both SNF-PDL and SNF-APTS. Interestingly, SNF-PDL-containing solutions

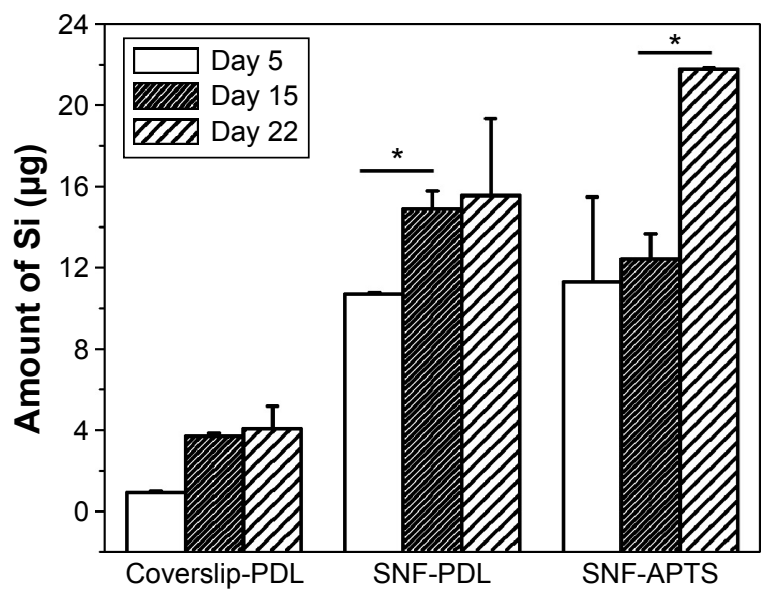

Figure 5 ICP-AES analysis of dissolved silicon from the coverslip-PDL, SNF-PDL, and SNF-APTS substrates immersed in PBS at $37^{\circ} \mathrm{C}$ up to 22 days $\left({ }^{*} P<0.01\right)$.

Notes: Unshaded, Day 5; dense shade, Day 15; and light shade, Day 22.

Abbreviations: SNF, silica nanofiber; ICP-AES, inductively coupled plasma atomic emission spectroscopy; coverslip-PDL, poly-D-lysine-treated coverslip; SNF-PDL, poly-D-lysine-treated silica nanofiber; SNF-APTS, (3-aminopropyl) trimethoxysilanemodified silica nanofiber; PBS, phosphate-buffered saline. demonstrated a greater difference in the amount of silicon dissolved between day $5(10.7 \pm 0.1 \mu \mathrm{g})$ and day $15(14.9 \pm 0.9 \mu \mathrm{g})$ (unpaired $t$-test, $P<0.01$ ) and an insignificant change from day 15 to day $22(15.6 \pm 3.7 \mu \mathrm{g})$ (unpaired $t$-test, $P>0.1$ ). The optical and electron microscopic examinations had also revealed that the fibers mostly disappeared around day 15 (Figure S1 for example of SNF-PDL on day 15). In contrast, the SNF-APTS substrate demonstrated an insignificant change in the amount of silicon dissolved between day 5 $(11.3 \pm 4.2 \mu \mathrm{g})$ and day $15(12.5 \pm 1.2 \mu \mathrm{g})$ (unpaired $t$-test, $P>0.1)$ and a more drastic difference between day 15 and day $22(21.8 \pm 0.1 \mu \mathrm{g})$ (unpaired $t$-test, $P<0.01)$. This result is in agreement with our observations of delayed nanofibers dissolution (Figure 3). In combination, the SEM and ICPAES analyses suggested that dissolution of covalently modified SNF-APTS was significantly hindered in comparison to SNF alone and SNF-PDL, which could be largely due to the increase in surface hydrophobicity as well as decrease in surface area of the substrate.

\section{Biocompatibility and neurite growth on surface-modified SNF substrates}

To characterize how different surface modifications may affect cell viability, the LIVE/DEAD assay was performed. Figure 6A shows that there is no significant difference in the viability of hippocampal neurons among the coverslip surface coated with PDL $(98.64 \% \pm 1.98 \%)$, SNF-PDL $(99.62 \% \pm 1.18 \%)$, and SNF-APTS $(99.93 \% \pm 0.27 \%)$ after $5 \mathrm{DIV}$. The result is in agreement with our previous findings that SNF material as well as APTS surface modification are nontoxic to cells. ${ }^{14}$ In order to verify the successful differentiation of neurons on various surfaces, neurons cultured on coverslip-PDL, SNF-PDL, and SNF-APTS substrates after 8 DIV were assessed by immunofluorescence staining. These images demonstrated that the neurons were able to adhere to the SNF-APTS substrate and the neurites of the differentiated neurons successfully elongated and extended over the substrate surface (Figure 6B-D). Similar results were obtained from the SNF-PDL substrate (Figure S2).

To examine the effect of cell-substrate interaction on the proper differentiation of neurons as well as the density and length of neurites, neurons seeded on coverslip-PDL, SNF-PDL, and SNF-APTS substrates at 8 DIV were immunocytochemically stained against microtubule-associated protein 2 antibody, and large stitched images of view field containing neurons with full neurite processes were obtained. Figure 7A-C shows that neurons grown on all three substrates revealed outgrowth of neurites, and the coverslip-PDL 

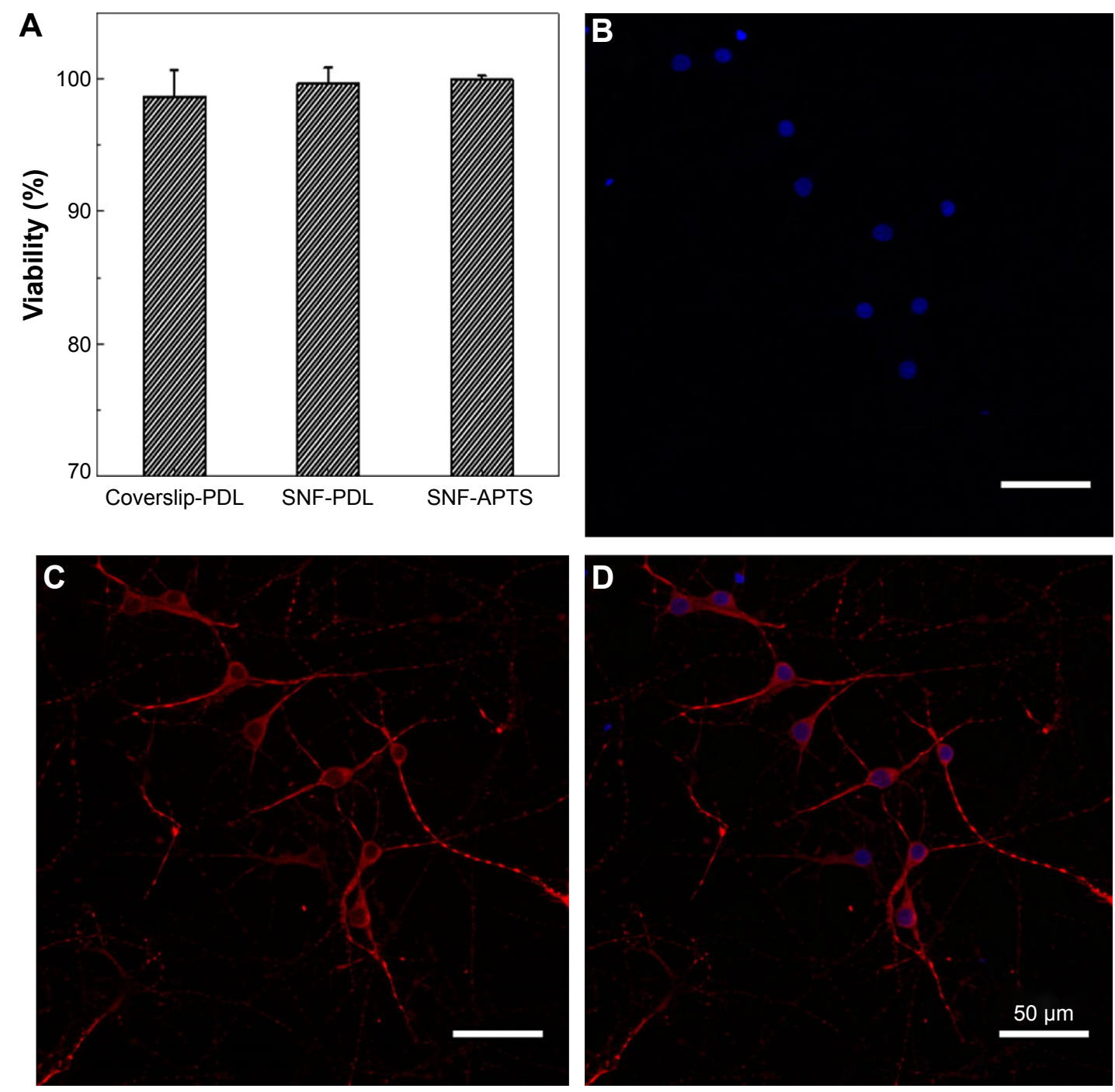

Figure 6 Viability and confocal microscopic images of EI 8 primary hippocampal neurons grown on three different substrates: coverslip-PDL, SNF-PDL, and SNF-APTS. Notes: Cell viabilities (A) were assessed using LIVE/DEAD ${ }^{\circledR}$ stain with dead cells labeled by Ethidium Homodimer-I and live cells by calcein AM after 5 DIV. After 8 DIV, cells were fixed and counter stained for nucleus (DAPI, blue) (B) and immunocytochemistry against neuronal marker (MAP2, red) (C). Merged images of the two stains are shown in panel (D). (Scale bars represent $50 \mu \mathrm{m}$ ).

Abbreviations: SNF, silica nanofiber; EI8, embryonic day 18; coverslip-PDL, poly-D-lysine-treated coverslip; SNF-PDL, poly-D-lysine-treated silica nanofiber; SNF-APTS, (3-aminopropyl) trimethoxysilane-modified silica nanofiber; calcein AM, calcein acetoxymethyl ester; DIV, days in vitro; DAPI, 4',6-diamidino-2-phenylindole; MAP2, microtubule-associated protein 2.

substrate had the least neurites with the longest length compared to the other two substrates. A quantitative illustration of the differences in neurite density (line diagram) and average neurite lengths (bar diagram) of the differentiated cells (Figure 7D) revealed that between the PDL-coated surfaces, comparing 2-D (coverslip-PDL) versus 3-D (SNF-PDL) substrates, the neurite density increased from $11.2 \pm 4.2$ to $42.6 \pm 14.8$ per image while the neurite length decreased from $57.6 \pm 4.0 \mu \mathrm{m}$ to $40.6 \pm 0.9 \mu \mathrm{m}$ (unpaired $t$-test, $P<0.01$ ). Neurons grown on the SNF-APTS substrate showed longer average neurite length $(46.8 \pm 1.5 \mu \mathrm{m})$ and lower neurite density (29.7 \pm 10.5 per image) than those on SNF-PDL substrates. These results are in line with the previous reports where the surface modifications with amino groups enhanced the cell attachment, neuronal differentiation, and excitatory synapse formation. ${ }^{46}$ We hypothesize that the higher neurite density on SNF-PDL substrate is due to both its larger surface area offered by the 3-D SNF structure, compared to the 2-D coverslip, and its possible higher amino density contributed by PDL coating.

The neurite length distribution was examined by the histogram analysis (Figure 7E). Although all three conditions produced a majority of neurites $<80 \mu \mathrm{m}$ long, $>14 \%$ of neurites from coverslip-PDL were longer than $160 \mu \mathrm{m}$, compared to $2 \%$ for SNF-PDL and $6 \%$ for SNF-APTS, which resulted in the higher overall average neurite length 

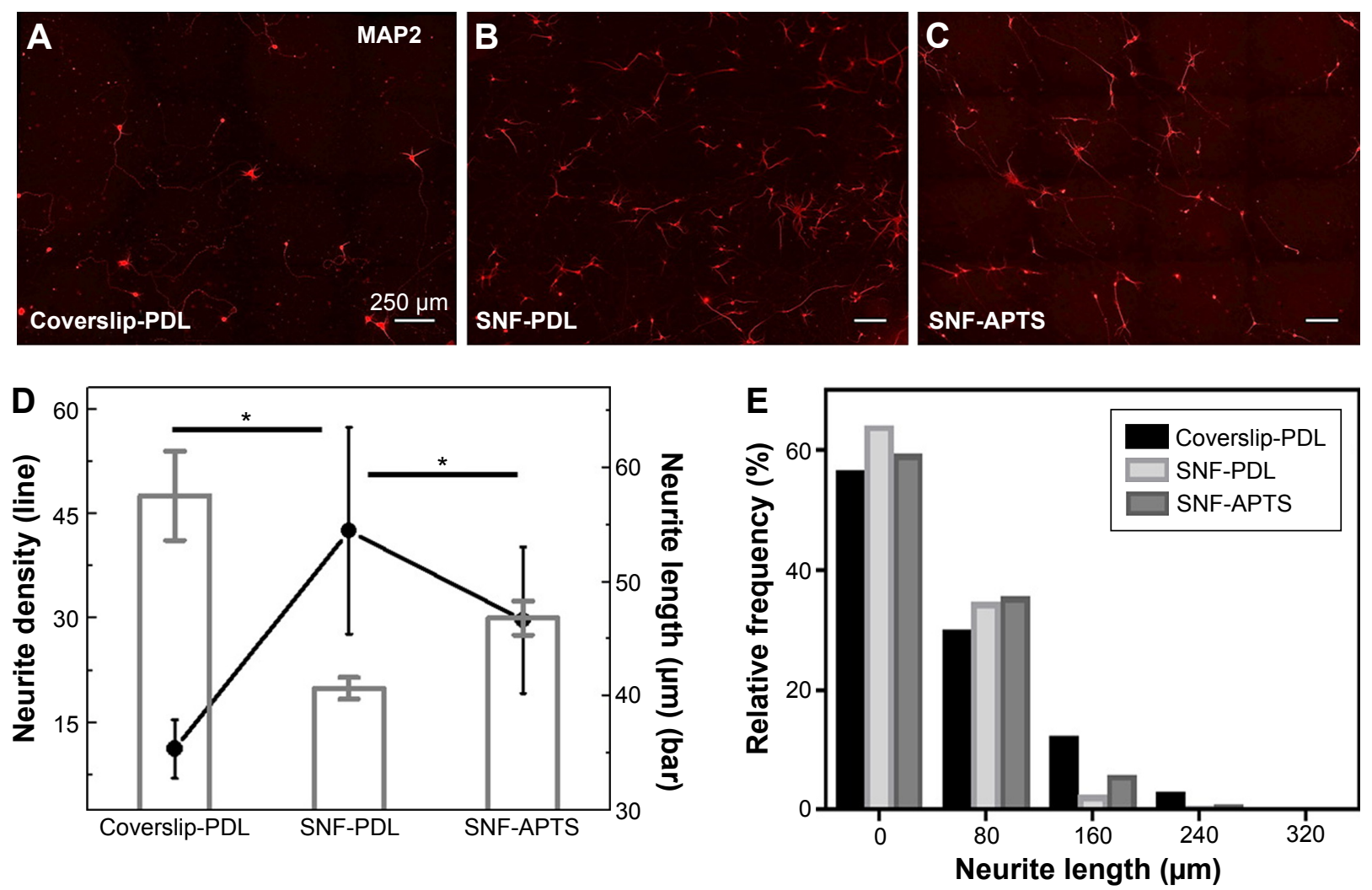

Figure 7 Large stitched fluorescence microscopy image from 16 individual scans of 8-10 DIV EI8 hippocampal primary neurons seeded on three different surfaces (A) coverslip-PDL, (B) SNF-PDL, and (C) SNF-APTS immunostained with neuronal marker (MAP2, red). Scale bars represent $250 \mu$ m. (D) Neurite density from the 20 images analyzed (as line graph) and the average neurite lengths (as bar graph, standard error of measurements as error bars) ( $* P<0.0 \mathrm{I}$ ). Neurite density was calculated by counting the number of neurites in each image $\left(3,496 \times 2,632 \mu \mathrm{m}^{2}\right)$ and $(\mathbf{E})$ relevant frequency histograms of neurite length on three substrates compared.

Abbreviations: SNF, silica nanofiber; DIV, days in vitro; EI8, embryonic day 18; coverslip-PDL, poly-D-lysine-treated coverslip; SNF-PDL, poly-D-lysine-treated silica nanofiber; SNF-APTS, (3-aminopropyl) trimethoxysilane-modified silica nanofiber; MAP2, microtubule-associated protein 2.

on the coverslip-PDL surfaces. We suggest that because 2-D coverslip-PDL had less neurites per area, the differentiated cells had to extend longer in order to seek out and synapse with neighboring processes. Thus, the length of the neurite may be dependent on the distance in between neurites before synapse could be made.

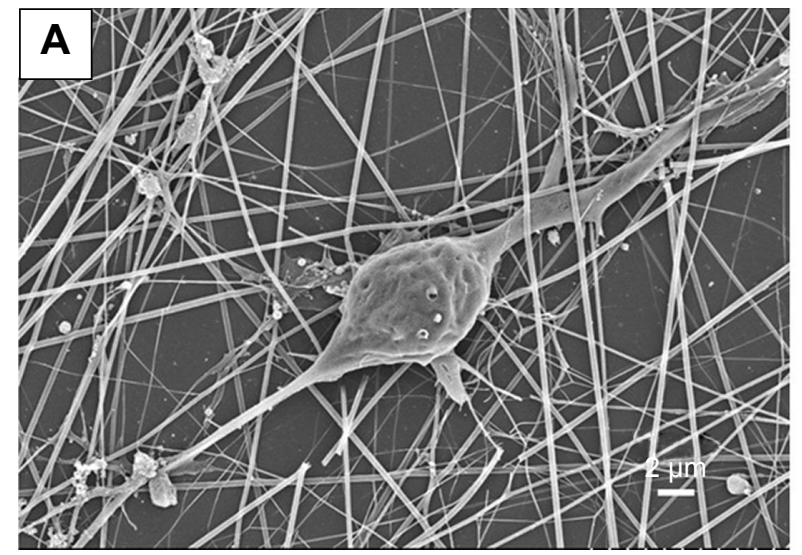

For structural visualization of the interaction between the neuron and the substrate, SEM images were acquired for closer inspection of the neuron morphology on the SNF-PDL substrate 10 days and 15 days postdifferentiation. Figure 8 revealed that the fiber substrate provided a relatively uniform, yet irregularly woven mat with interconnected voids for the

Figure 8 SEM images of neurons grown on the SNF-PDL substrates 10 days (A) and 15 days (B) postdifferentiation.

Notes: (A) Scale bars represent $2 \mu \mathrm{m}$. Inset in (B) is magnification of the corresponding surfaces. Scale bars represent $2 \mu \mathrm{m}$ in $\mathbf{A}$ and $\mathbf{B}$, and I $\mu \mathrm{m}$ in inset. Abbreviations: SNF, silica nanofiber; SEM, scanning electron microscopy; SNF-PDL, poly-D-lysine-treated silica nanofiber.

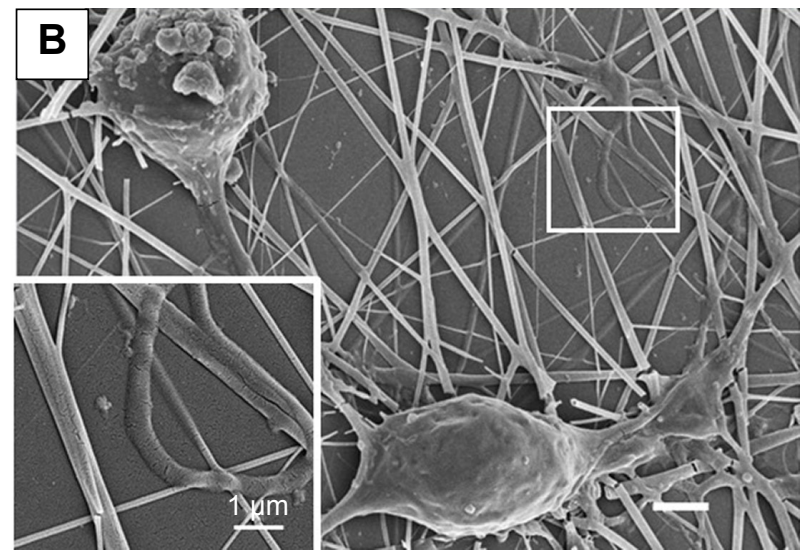


neurons to grow on. Interestingly, neurites were interwoven with the substrate at various levels, as shown in the top right corner of Figure 8A. Moreover, the neurites extend in multiple directions along the randomly directed fibers, eventually becoming difficult to distinguish from fibers. In contrast to neural stem cells that grew only along the fibers, ${ }^{14}$ neurites from these primary neurons appeared to grow both along and across the gaps between the fibers.

\section{Dissolution of surface-modified SNF substrates with hippocampal neurons}

In order to study the dissolution behavior of SNF in the presence of neurons, neurons were cultured on various substrates in NbActiv1 media up to 15 days, the usual duration where most of SNF has been dissolved in PBS buffer (Figure S1), and the NbActiv1 media was collected and assessed by ICP-AES as shown in Figure 9. The amounts of silicon from coverslip-PDL control group fell below the limit of detection $([\mathrm{LOD}]=15 \mathrm{ppb})$ in all these measurements. The inferior LOD from ICP-AES was largely due to the high sodium ion concentration in the NbActiv1 media in comparison with that of the PBS media ( $\mathrm{LOD}=7.0 \mathrm{ppb}$ ). Later, the silicon contents in both media, which were collected from SNF-PDL and SNF-APTS, have decreased in contrast to that in PBS buffer. The dissolved silicon amounts decreased from day 5 (15.3 $\pm 0.1 \mu \mathrm{g}$ for SNF-PDL and $11.1 \pm 0.3 \mu \mathrm{g}$ for SNF-APTS) to day $15(12.7 \pm 0.2 \mu \mathrm{g}$ for SNF-PDL and 7.6 $\pm 0.1 \mu \mathrm{g}$ for SNF-APTS) (unpaired $t$-test, $P<0.01$ ). We attribute this

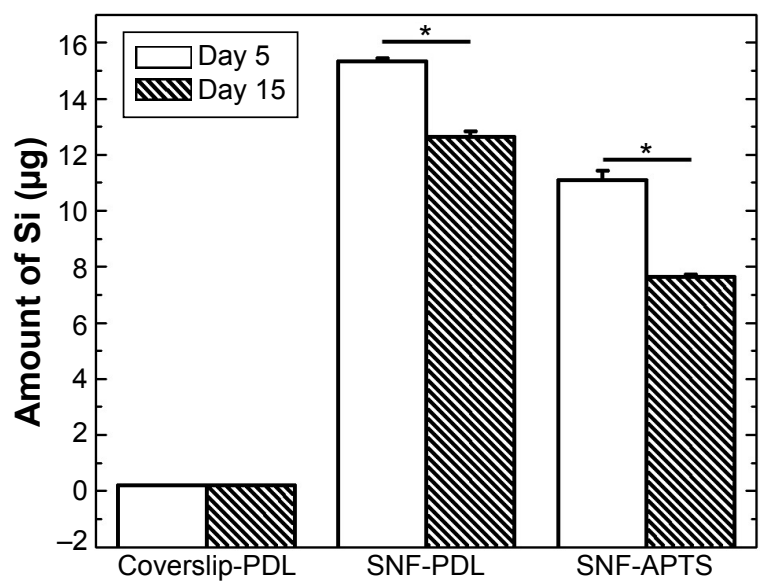

Figure 9 ICP-AES analysis of dissolved silicon from NbActivl media cultured with hippocampal neurons grown on the coverslip-PDL, SNF-PDL, and SNF-APTS substrates up to 15 days $(* P<0.01)$.

Note: Unshaded, day 5 and dense shade day 15.

Abbreviations: SNF, silica nanofiber; ICP-AES, inductively coupled plasma-atomic emission spectroscopy; coverslip-PDL, poly-D-lysine-treated coverslip; SNF-PDL, poly-D-lysine-treated silica nanofiber; SNF-APTS, (3-aminopropyl) trimethoxysilanemodified silica nanofiber. difference to the media composition that may interfere with ICP-AES measurements. Specifically, the amount of silicon in solution may decrease as a result of redeposition of silica with calcium or magnesium ions in solution, as noted by $\mathrm{He}$ et al. ${ }^{32}$ Since NbActiv1 media contain millimolar levels of calcium and magnesium ions, while PBS buffer does not, we believe that the presence of calcium and magnesium ions could have led to the observed decrease in the amount of silicon measured by ICP. We note that the toxicity of silicic acid, the major form of silica dissolution product, to $\mathrm{B} 50$ cells, which are rat neuronal cells in culture has previously been evaluated using the MTT assay, ${ }^{47}$ indicating no significant toxicity $<100 \mu \mathrm{M}$ level. This result is consistent with our observations, which showed no cytotoxicity at day 5 (Figure 6). Even at longer neuron growth time, the concentrations of dissolved silicon did not surpass $60 \mu \mathrm{M}$ in our study.

It is important to note that the fibers shown in Figure 8B resemble those in Figure 3E with a flattened morphology and multiple hollow-looking fibers, which indicated that dissolution of SNF is still occurring in the presence of biological species. Inset in Figure 8B shows a zoomed-in view of the region where a loop of neurite lay on flattened dissolving fibers. Comparing dissolution process shown in Figure 8 (day 10 and day 15) with that in Figure 3E (day 11), we noted that the dissolution rate in the presence of biological species was reduced, which could be due to cell secretions that hindered the dissolution process. Similar observations have been made on colloidal silica particles where dissolution in $10 \%$ bovine serum media has resulted in a reduced dissolution rate when compared to that in PBS, yet did not prevent dissolution completely. ${ }^{48}$

\section{Conclusion}

In summary, we demonstrate that the surface-modified SNFs are biocompatible and degradable substrates to promote neuronal cell attachment and differentiation. The results showed that dissolution occurred through a corrosion-like manner by enlarging porous structures, leading to the loss of structural integrity. Covalently modified SNF-APTS with more hydrophobic surfaces and smaller surface areas yielded substantially slower dissolution when compared with the physically modified SNF-PDL. In addition, the 3-D structures providing more surface area as well as amino groups were crucial for enhancing cell attachment and promoting neurite density. More importantly, the inorganic substrate dissolved under physiological conditions in the presence of biological species growth made it a simple degradable implant substrate 
in contrast to the enzymatic degradable organic polymer alternatives. The last tunability of the dissolution rate via various surface functionalization provided a feasible alternative for controlled release application.

\section{Acknowledgments}

The support of this research by the Branfman Family Foundation and the Sunquist Fund is gratefully acknowledged. We warmly thank URGO at Augsburg College and Quasi Endowment Fund from Concordia University, St Paul for the support provided. This work was also supported in part by the National Science Foundation through the University of Minnesota MRSEC under Award Number DMR-0819885. We also gratefully acknowledge Ministry of Science and Technology, Taiwan, Republic of China (102-2632-M033-001-MY3), and Chung Yuan Christian University, Taiwan, Republic of China. We thank Brian Barber at the Research Analytical Laboratory, University of Minnesota, for assistance with ICP-AES analysis.

\section{Disclosure}

The authors report no conflicts of interest in this work.

\section{References}

1. Wang TY, Forsythe JS, Nisbet DR, Parish CL. Promoting engraftment of transplanted neural stem cells/progenitors using biofunctionalised electrospun scaffolds. Biomaterials. 2012;33:9188-9197.

2. Horne MK, Nisbet DR, Forsythe JS, Parish CL. Three-dimensional nanofibrous scaffolds incorporating immobilized BDNF promote proliferation and differentiation of cortical neural stem cells. Stem Cells Dev. 2010;19:843-852.

3. Ducic I, Maloney CT Jr, Dellon AL. Reconstruction of the spinal accessory nerve with autograft or neurotube? Two case reports. J Reconstr Microsurg. 2005;21:29-33.

4. O'Brien FJ. Biomaterials \& amp; scaffolds for tissue engineering. Mater Today. 2011;14:88-95.

5. Saglam A, Perets A, Canver AC, et al. Angioneural crosstalk in scaffolds with oriented microchannels for regenerative spinal cord injury repair. J Mol Neurosci. 2013;49:334-346.

6. Yeh LC, Dai CF, Yeh JM, et al. Neat poly(ortho-methoxyaniline) electrospun nanofibers for neural stem cell differentiation. $J$ Mater Chem B. 2013;1:5469-5477.

7. Nisbet DR, Yu LM, Zahir T, Forsythe JS, Shoichet MS. Characterization of neural stem cells on electrospun poly(epsilon-caprolactone) submicron scaffolds: evaluating their potential in neural tissue engineering. J Biomate Sci Polym Ed. 2008;19:623-634.

8. Li YK, Chen YC, Jiang KJ, Wu JC, Chen-Yang YW. Three-dimensional arrayed amino aerogel biochips for molecular recognition of antigens. Biomaterials. 2011;32:7347-7354.

9. Li YK, Yang DK, Chen YC, Su HJ, Wu JC, Chen-Yang YW. A novel three-dimensional aerogel biochip for molecular recognition of nucleotide acids. Acta Biomater. 2010;6:1462-1470.

10. $\mathrm{Vu} \mathrm{D,} \mathrm{Li} \mathrm{Z,} \mathrm{Zhang} \mathrm{H,} \mathrm{et} \mathrm{al.} \mathrm{Adsorption} \mathrm{of} \mathrm{Cu}$ (II) from aqueous solution by anatase mesoporous $\mathrm{TiO}_{2}$ nanofibers prepared via electrospinning. J Colloid Interface Sci. 2012;367:429-435.

11. Zhai W, Lu H, Chen L, et al. Silicate bioceramics induce angiogenesis during bone regeneration. Acta Biomater. 2012;8:341-349.
12. Heinemann S, Heinemann C, Bernhardt R, et al. Bioactive silicacollagen composite xerogels modified by calcium phosphate phases with adjustable mechanical properties for bone replacement. Acta Biomater. 2009;5:1979-1990.

13. López T, Bata-García JL, Esquivel D, et al. Treatment of Parkinson's disease: nanostructured sol-gel silica-dopamine reservoirs for controlled drug release in the central nervous system. Int J Nanomed. 2011;6: $19-31$.

14. Chen WS, Hsieh PH, Yang WN, et al. Chemically modified electrospun silica nanofibers for promoting growth and differentiation of neural stem cells. J Mater Chem B. 2014;2:1205-1215.

15. Chen G, Xu Y, Yu DG, et al. Structure-tunable Janus fibers fabricated using spinnerets with varying port angles. Chem Commun. 2015;51: 4623-4626.

16. Wu YH, Yu DG, Li XY, Diao AH, Illangakoon U, Williams G. Fastdissolving sweet sedative nanofiber membranes. J Mater Sci. 2015;50: 3604-3613.

17. Yu DG, Li XY, Wang X, Yang JH, Bligh SWA, Williams GR. Nanofibers fabricated using triaxial electrospinning as zero order drug delivery systems. ACS Appl Mater Interfaces. 2015;7:18891-18897.

18. Yu DG, White K, Chatterton N, Li Y, Li L, Wang X. Structural lipid nanoparticles self-assembled from electrospun core-shell polymeric nanocomposites. $R S C A d v$. 2015;5:9462-9466.

19. Wang X, Yu DG, Li XY, Bligh SWA, Williams GR. Electrospun medicated shellac nanofibers for colon-targeted drug delivery. Int $J$ Pharm. 2015;490:384-390.

20. Lai CY, Trewyn BG, Jeftinija DM, et al. A mesoporous silica nanosphere-based carrier system with chemically removable $\mathrm{CdS}$ nanoparticle caps for stimuli-responsive controlled release of neurotransmitters and drug molecules. J Am Chem Soc. 2003;125: 4451-4459.

21. Cho Y, Shi R, Borgens RB. Chitosan produces potent neuroprotection and physiological recovery following traumatic spinal cord injury. $J$ Exp Biol. 2010;213:1513-1520.

22. Barandeh F, Nguyen P-L, Kumar R, et al. Organically modified silica nanoparticles are biocompatible and can be targeted to neurons in vivo. PLoS One. 2012; 7:e29424.

23. Labow RS, Meek E, Santerre JP. The biodegradation of poly(urethane)s by the esterolytic activity of serine proteases and oxidative enzyme systems. J Biomate Sci Polym Ed. 1999;10:699-713.

24. Gan Z, Liang Q, Zhang J, Jing X. Enzymatic degradation of poly( $\varepsilon-$ caprolactone) film in phosphate buffer solution containing lipases. Polym Degrad Stab. 1997;56:209-213.

25. Darwis D, Mitomo H, Enjoji T, Yoshii F, Makuuchi K. Enzymatic degradation of radiation crosslinked poly(E-caprolactone). Polym Degrad Stab. 1998;62:259-265.

26. Liu Y, Li Y, Liu S, Li J, Yao S. Monitoring the self-assembly of chitosan/ glutaraldehyde/cysteamine/Au-colloid and the binding of human serum albumin with hesperidin. Biomaterials. 2004;25:5725-5733.

27. Bruggeman JP, de Bruin B-J, Bettinger CJ, Langer R. Biodegradable poly(polyol sebacate) polymers. Biomaterials. 2008;29:4726-4735.

28. Wang J, Boutin KG, Abdulhadi O, et al. Fully biodegradable airway stents using amino alcohol-based poly(ester amide) elastomers. Adv Healthc Mater. 2013;2:1329-1336.

29. Wang X, Zhu J, Yin L, et al. Fabrication of electrospun silica-titania nanofibers with different silica content and evaluation of the morphology and osteoinductive properties. J Biomed Mater Res A. 2012;100A: 3511-3517.

30. Sun JY, Yang YS, Zhong J, Greenspan DC. The effect of the ionic products of bioglass dissolution on human osteoblasts growth cycle in vitro. J Tissue Eng Regen Med. 2007;1:281-286.

31. Valerio P, Pereira MM, Goes AM, Leite MF. The effect of ionic products from bioactive glass dissolution on osteoblast proliferation and collagen production. Biomaterials. 2004;25:2941-2948.

32. He Q, Shi J, Zhu M, Chen Y, Chen F. The three-stage in vitro degradation behavior of mesoporous silica in simulated body fluid. Micropor Mesopor Mater. 2010;131:314-320. 
33. Lin YS, Hurley KR, Haynes CL. Critical considerations in the biomedical use of mesoporous silica nanoparticles. J Phys Chem Lett. 2012;3: 364-374.

34. Xu H, Fan X, Wu X, Tang J, Yang H. Neural precursor cells differentiated from mouse embryonic stem cells relieve symptomatic motor behavior in a rat model of Parkinson's disease. Biochem Biophys Res Commun. 2004;326:115-122.

35. Jiang X, Cao HQ, Shi LY, et al. Nanofiber topography and sustained biochemical signaling enhance human mesenchymal stem cell neural commitment. Acta Biomater. 2012;8:1290-1302.

36. Ravichandran R, Gandhi S, Sundaramurthi D, Sethuraman S, Krishnan UM. Hierarchical mesoporous silica nanofibers as multifunctional scaffolds for bone tissue regeneration. J Biomate Sci Polym Ed. 2013;24:1988-2005.

37. Yamaguchi T, Sakai S, Kawakami K. Application of silicate electrospun nanofibers for cell culture. J Solgel Sci Technol. 2008;48:350-355.

38. Liu T, Wimalasena J, Bowen RL, Atwood CS. Luteinizing hormone receptor mediates neuronal pregnenolone production via up-regulation of steroidogenic acute regulatory protein expression. J Neurochem. 2007;100:1329-1339.

39. Yang ML, Hasadsri L, Woods WS, et al. Dynamic transport and localization of alpha-synuclein in primary hippocampal neurons. Mol Neurodegener. 2010;5:9.

40. Ren YJ, Zhang H, Huang H, George JM. In vitro behavior of neural stem cells in response to different chemical functional groups. Biomaterials. 2009;30:1036-1044.
41. Amritraj A, Wang Y, Revett TJ, Vergote D, Westaway D, Kar S. Role of cathepsin D in U18666A-induced neuronal cell death: potential implication in Niemann-Pick type C disease pathogenesis. J Biol Chem. 2013;288:3136-3152.

42. Lutzke A, Pegalajar-Jurado A, Neufeld BH, Reynolds MM. Nitric oxidereleasing S-nitrosated derivatives of chitin and chitosan for biomedical applications. J Mater Chem B. 2014;2:7449-7458.

43. Koito H, Li J. Preparation of rat brain aggregate cultures for neuron and glia development studies. J Vis Exp. 2009;31:1304.

44. Howarter JA, Youngblood JP. Optimization of silica silanization by 3-aminopropyltriethoxysilane. Langmuir. 2006;22:11142-11147.

45. Li D, Zhu Y, Mao C. One-pot synthesis of surface roughness controlled hollow silica spheres with enhanced drug loading and release profiles under ambient conditions in aqueous solutions. JMater Chem B. 2013;1: $5515-5520$.

46. Li HL, Zhang H, Huang H, et al. The effect of amino density on the attachment, migration, and differentiation of rat neural stem cells in vitro. Mol Cell. 2013;35:436-443.

47. Mayne AH, Bayliss SC, Barr P, Tobin M, Buckberry LD. Biologically interfaced porous silicon devices. Phys Status Solidi (a). 2000;182: 505-513.

48. Finnie K, Waller D, Perret F, et al. Biodegradability of sol-gel silica microparticles for drug delivery. J Solgel Sci Technol. 2009;49: 12-18. 


\section{Supplementary materials}

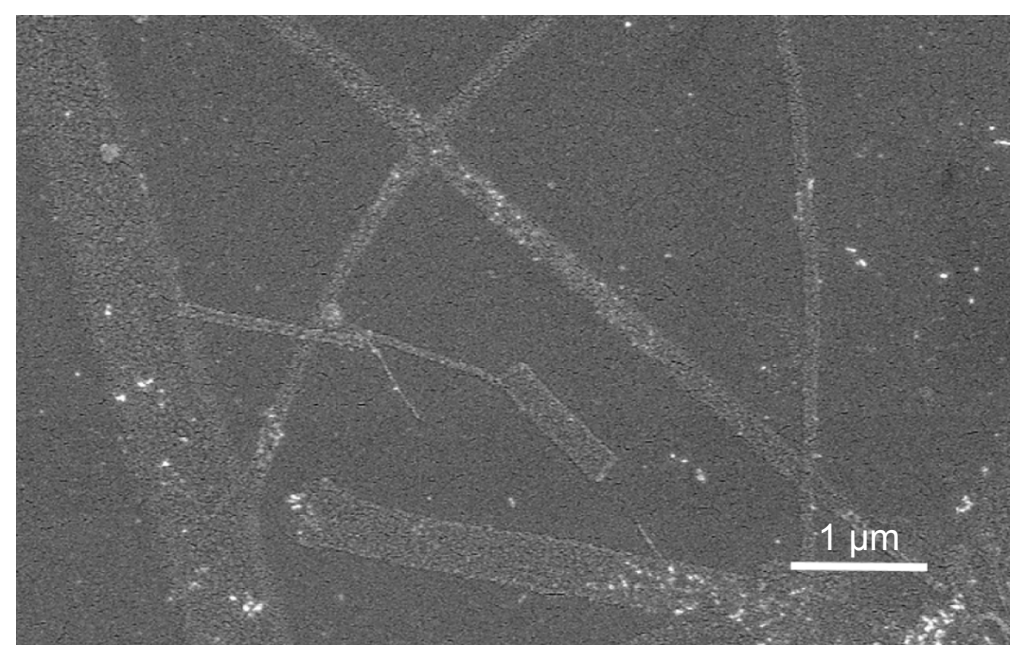

Figure SI Representative scanning electron micrographs of SNF-PDL on Day I5.

Abbreviation: SNF-PDL, poly-D-lysine-treated silica nanofiber.
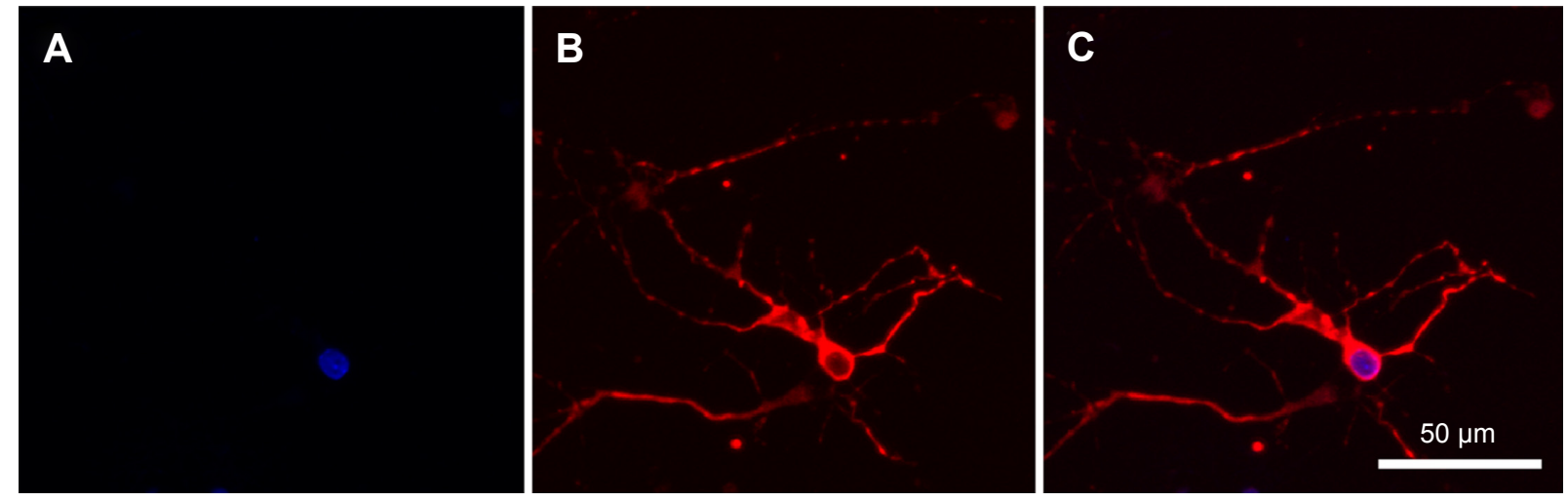

Figure S2 Confocal microscopic images of E18 primary hippocampal neurons grown on SNF-PDL.

Notes: Cells were fixed and counter stained for nucleus (DAPI, blue) (A) and immunocytochemistry against neuronal marker (MAP2, red) (B). Merged images of the two stains are shown in panel $(\mathbf{C})$. Scale bars represent $50 \mu \mathrm{m}$.

Abbreviations: EI8, embryonic day 18; SNF-PDL, poly-D-lysine-treated silica nanofiber.

\section{Publish your work in this journal}

The International Journal of Nanomedicine is an international, peerreviewed journal focusing on the application of nanotechnology in diagnostics, therapeutics, and drug delivery systems throughou the biomedical field. This journal is indexed on PubMed Central, MedLine, CAS, SciSearch ${ }^{\circledR}$, Current Contents ${ }^{\circledR} /$ Clinical Medicine,
Journal Citation Reports/Science Edition, EMBase, Scopus and the Elsevier Bibliographic databases. The manuscript management system is completely online and includes a very quick and fair peer-review system, which is all easy to use. Visit http://www.dovepress.com/ testimonials.php to read real quotes from published authors.

\footnotetext{
Submit your manuscript here: http://www.dovepress.com/international-journal-of-nanomedicine-journal
} 